\title{
Antitumor activity of a novel small molecule TLR7 agonist via immune response induction and tumor microenvironment modulation
}

\author{
YUWEN DIAO $^{1-3^{*}}$, XIAODONG WANG $^{1,2^{*}}$, YANYAN WAN $^{1,2^{*}}$, JINGJING ZHONG $^{1,2^{*}}$, DONG GAO $^{1,2}$, \\ YU LIU ${ }^{1,2}$, NINGNING GAO ${ }^{1,2}$, WANG LI ${ }^{1,2}$, BING LIU ${ }^{1,2}$, XINPING HUANG ${ }^{1,2}$, ZHENCHAO JIN $^{1,2}$, \\ BOYA PENG ${ }^{1,2}$, ZHULIN WANG ${ }^{1,2}$, LI FU $^{1}$, SIPING CHEN ${ }^{1}$ and GUANGYI JIN ${ }^{1,2}$ \\ ${ }^{1}$ Cancer Research Center, National-Regional Key Technology Engineering Laboratory for Medical Ultrasound, \\ School of Medicine, Shenzhen University; ${ }^{2}$ Shenzhen Engineering Laboratory of Synthetic Biology, \\ Shenzhen, Guangdong 518060; ${ }^{3}$ Advanced Institute for Medical Sciences, \\ Dalian Medical University, Dalian, Liaoning 116044, P.R. China
}

Received August 29, 2015; Accepted October 11, 2015

DOI: $10.3892 /$ or.2015.4436

\begin{abstract}
Immunotherapy is emerging as a powerful and active tumor-specific approach against cancer via triggering the immune system. Toll-like receptors (TLRs) are fundamental elements of the immune system, which facilitate our understanding of the innate and adaptive immune pathways. TLR agonists used as single agents can effectively eradicate tumors due to their potent stimulation of innate and adaptive immunity. We examined the effects of a novel adenine type of TLR7 agonists on both innate and adaptive immune activation in vitro and in vivo. We established the local and distant tumor-bearing mice derived from murine mammary carcinoma cell line (4T1) to model metastatic disease. Our data demonstrated that SZU101 was able to stimulate innate immune cells to release cytokines at the very high level compared with LPS at the same or lower concentration. Locally intratumoral SZU101 injection can elicit a systemic antitumor effect on murine breast tumor model. SZU101 affected the frequency of intratumoral immune cell infiltration, including the percentage of $\mathrm{CD}^{+}$and $\mathrm{CD}^{+}$increase, and the ratio of Tregs decrease. Our data reveal that the antitumor effect of SZU101 is associated with multiple mechanisms, inducing tumor-specific immune response, activation of innate immune cells and modulation of the tumor microenvironment.
\end{abstract}

Correspondence to: Dr Guangyi Jin, Cancer Research Center, National-Regional Key Technology Engineering Laboratory for Medical Ultrasound, School of Medicine, Shenzhen University, Shenzhen, Guangdong 518060, P.R. China

E-mail: gyjin@szu.edu.cn

*Contributed equally

Key words: adenine derivatives, immunotherapy, toll-like receptor 7 agonist, solid tumor, tumor microenvironment

\section{Introduction}

Toll-like receptors (TLRs) are fundamental elements of the immune system, which facilitate our understanding of the innate and adaptive immune pathways (1). TLRs are expressed on a variety of cells, including B cells, specific types of T cells, DCs and macrophages. All the TLRs can recognize distinct molecular components of bacteria, viruses, fungi or other pathogens $(1,2)$. Also some synthetic small molecules can activate certain TLR pathways (3). Particularly, TLR ligands can control the activation of dendritic cells (DCs), trigger the maturation program of DCs and lead to the secretion of proinflammatory cytokines (4). Most TLR ligands possess important properties that can initiate the host innate and adaptive immune response for the immunotherapy against cancer (5). They have the ability to promote tumor-specific Th1 immune response and cytotoxic T lymphocyte responses $(6,7)$.

Most conventional cancer therapies (surgery, chemotherapy and radiation) are not tumor-specific, so immunotherapy is emerging as a powerful tumor-specific approach to cancer treatment. However, some immunotherapies are likely to have a negative influence of the tumor immune escape. Tumor cells generated occasionally can be recognized and removed as non-self by immune cells. However, cancer progression occurs as a result of a failure in immune surveillance. Increasing research effort is focused on dysfunctional immune cells and immune cells in the tumor microenvironment (8-10). The goal of cancer immunotherapy is directed not only at stimulation of innate and adaptive immune but reversal of immune dysfunction. Recent reports based on the antitumor effect of TLR agonists provide new evidence that TLR agonists can modulate the tumor microenvironment, especially the type, location, and density of immune cells. FDA has approved seven TLR agonists on cancer immunotherapy, including imiquimod (TLR7 agonists), BCG (mixed TLR2/TLR4 agonists) and glucopyranosyl lipid adjuvant (TLR4 agonists) (11). As is known that only TLR 7 ligand can be a small-molecule synthetic agonist, several synthesized low molecular weight TLR7 agonists were 
found, including imidazoquinolines and purine-like molecules, to activate immune cells via the TLR7-MyD88-dependent signaling pathway $(12,13)$. Imiquimod is being successfully used for the treatment of many primary skin tumors and cutaneous metastases as the single antitumor agent with immunostimulatory capacity $(11,14)$.

In the present study, we examined the effects of a novel adenine type of TLR7 agonists (SZU101) on the magnitude of both innate and adapt immune activation in vitro and in vivo. We established local and distant tumor-bearing mice derived from murine mammary carcinoma cell line (4T1) to model metastatic disease. We report on the elicited antitumor effect on tumors by multiple mechanisms, inducing tumor-specific immune response, activating innate immune cells and modulation of the tumor microenvironment. We also found that intratumoral administration of SZU101 can change the tumor microenvironment and delay distant tumor growth.

\section{Materials and methods}

Cell line and mice. The 4T1 were maintained in our lab and cultured in RPMI-1640, supplemented with $10 \%$ fetal bovine serum (FBS), $100 \mu \mathrm{g} / \mathrm{ml}$ penicillin and $100 \mu \mathrm{g} / \mathrm{ml}$ streptomycin (all from Hyclone, Logan, UT, USA). Cells were cultured at $37^{\circ} \mathrm{C}$ in a humidified atmosphere with $5 \% \mathrm{CO}_{2}$. Female BALB/c mice at 6 weeks of age were purchased from the Medical Laboratory Animal Centre, Guangdong, China. All animals were housed in laminar flow cages and were permitted ad lib access to sterile food and water. The experiments were carried out in accordance with recommendations cited in the Guide for the Care and Use of Laboratory Animals of the Medical Laboratory Animal Center of Guangdong, China.

Synthesis of TLR7 agonist. TLR7 agonist (SZU101) was synthesized in our laboratory according the following scheme (15).

Mouse model and treatments. The animals were injected subcutaneously with $100 \mu 1$ of $1.5 \times 10^{5} 4 \mathrm{~T} 1$ cells in PBS. The first injection was on day 0 in the right flank, and the second injection was on day 3 in the left flank. Mice were randomized at day 7 after inoculation to treatment by intratumoral injection with $0.1 \mathrm{ml}$ of either $1 \mathrm{mg} / \mathrm{ml}(\sim 5 \mathrm{mg} / \mathrm{kg})$ TLR7 agonist or placebo control (PBS, $\mathrm{pH}$ 7.2) in the right flank tumor every three days. Mice were sacrificed on day 30 .

Western blot analysis. Cells were lysed by Cell Lysis Buffer (Beyotime Institute of Biotechnology, China). Total protein was measured with a BCA assay kit (Bio-Rad Laboratories, Hercules, CA, USA). Samples were loaded onto SDS-polyacrylamide gels, transferred onto microporous polyvinylidene difluoride membranes and incubated with appropriate antibodies. Blotting was performed with the following primary antibodies: I $\kappa \mathrm{B} \alpha, \mathrm{NF}-\kappa \mathrm{Bp} 65, \mathrm{mTLR} 7, \beta$-actin and GAPDH, horseradish peroxidase-conjugated anti-mouse or anti-rabbit secondary antibody (1:1,500 dilution; Cell Signaling Technology, Inc., Danvers, MA, USA). Protein bands were visualized using ECL substrate (Pierce, Rockford, IL, USA).

Determination of cytokine production in vitro. Mouse spleen lymphocytes, BMDC and NK cells were isolated from BALB/c mice and grown in RPMI-1640 medium with $10 \%$ FBS. Cells were seeded in 24-well plates at a density of $5 \times 10^{4}$ cells per well. For spleen lymphocytes and NK cells, compounds were added to 24-h cultures at a final concentration ranging from 5 to $100 \mu \mathrm{M}$ or as otherwise indicated. For BMDC, compounds were added to 6-day cultures, and they were incubated for $24 \mathrm{~h}$, culture supernatants were collected and assayed for cytokine inductions by enzyme-linked immunosorbent assay (ELISA) (eBioscience, Inc., San Diego, CA, USA), according to the manufacturer's instructions. Murine macrophage-like cell line, RAW264.7 cells, was used as murine macrophage to determin the cytokines. The data were calculated from triplicate wells and are presented as a mean $\pm \mathrm{SD}$.

Determinations of antibody titers. On day 30, mice were sacrificed, blood samples were collected from the mice and centrifuged at 3,000 x g for $15 \mathrm{~min}$ to obtain serum samples. Antibody titers in serum were determined by ELISA method using an alkaline phosphate-conjugated detection antibody (Millipore, Billerica, MA, USA) for 4T1 antibody, IgG1 and IgG2a.

Determinations of CTL. At the time of sacrifice, lymphocytes, separated from the spleen of each mouse by Mouse Lymphocyte Separation medium (Dakewe, Beijing, China), were used as effectors. 4T1 tumor cells were used as target cells and incubated with lymphocytes for $4 \mathrm{~h}$ at an effector-to-target cell ratio of 100:1. Cytotoxicity was also measured by LDH method using Non-Radioactive Cytotoxicity assay (Promega, Madison, WI, USA), according to the supplier's manual.

Determinations of $A D C C$. At the time of sacrifice, serum samples from the mice were 1:25 diluted, and incubated with $4 \mathrm{~T} 1$ tumor cells for $30 \mathrm{~min}$ at $37^{\circ} \mathrm{C}$. NK cells, isolated from normal BALB/c mouse by Mouse NK cells Separation kit (Hao Yang, Tianjin, China), were used as effectors and seeded with the antibody-labeled 4T1 cells for $4 \mathrm{~h}$ at an effector-to-target cell ratio of 30:1. Cytotoxicity was measured by LDH method using Non-Radioactive Cytotoxicity assay (Promega), according to the supplier's manual. Briefly, after incubation, culture supernatants were transferred to an ELISA plate, followed by the addition of substrate solution for $30 \mathrm{~min}$ at room temperature. Finally, stop solution was filled in, and the optical density was measured at $490 \mathrm{~nm}$ with a spectrophotometer (BioTek, Winooski, VT, USA).

Flow cytometric analysis (16). On day 30, mice were sacrificed. Spleens were homogenized by repeated pipetting and filtered through a 70- $\mu \mathrm{m}$ nylon filter. Tumors from each group were minced with scissors prior to incubation with $1 \mathrm{mg} / \mathrm{ml}$ final concentration clostridiopeptidase A (Sigma-Aldrich, St. Louis, MO, USA), $0.25 \%$ trypsin (Hyclone) and $0.2 \mathrm{mg} / \mathrm{ml}$ DNase (Sigma) for $30 \mathrm{~min}$ at $37^{\circ} \mathrm{C}$. Single cell suspensions of splenocytes and tumors were collected and washed with FACS (5\% calf serum in PBS) 3 times and incubated with FACS for $1 \mathrm{~h}$, stained with appropriate antibodies at $1 \mu \mathrm{g} / \mathrm{ml}$ final concentration, on ice overnight and then washed with FACS 3 times and immediately analyzed by flow cytometry (Becton-Dickinson, San Jose, CA, USA). For intracellular staining, samples were fixed and permeabilized before incubation with antibody. Antibodies used for flow cytometry were purchased 

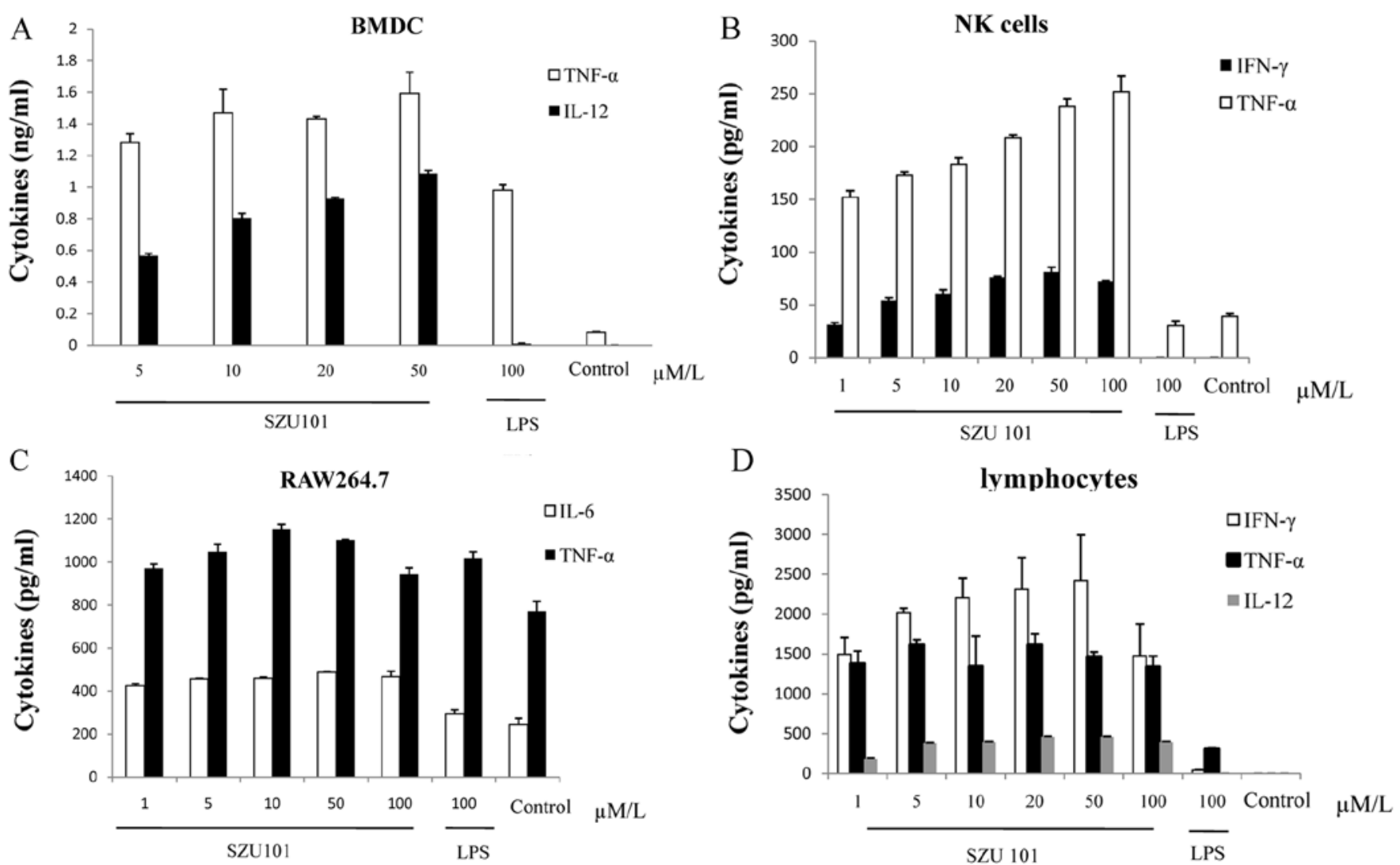

Figure 1. In vitro cytokine release in response to SZU101. BMDC (A), NK cells (B), spleen lymphocytes isolated from Balb/c mice (C) and RAW264.7 (D) were stimulated with SZU101 at 5, 10,20,50 and $100 \mu \mathrm{M}$ concentrations and LPS at $100 \mu \mathrm{M}$ as positive control for $24 \mathrm{~h}$. Cytokine levels were determined by ELISA. The error bars indicate the SD.

from eBioscience (PE-anti-mouse CD4, APC-anti-mouse CD25, FITC-anti-mouse Foxp3, APC-anti-mouse CD8 and FITC-anti-mouse CD3). Data were analyzed with FlowJo software (Tree Star, Inc., Ashland, OR, USA).

Statistical analysis. Statistical comparisons of mean values were performed using the Student's t-test. $\mathrm{P}<0.05$ was considered to indicate a statistically significant difference.

\section{Results}

Potent in vitro cytokine release in response to SZU101. To investigate the potency on murine TLR7 and the immunological activity of SZU101, bone marrow derived dendritic cells (BMDC), mouse nature killer cells (NK) and spleen lymphocytes isolated from BALB/c mice were stimulated with SZU101 at 5, 10, 20,50 and $100 \mu \mathrm{M}$ concentrations and LPS at $100 \mu \mathrm{M}$ as positive control in vitro (Fig. 1). RAW264.7 cells were treated as mentioned above. The values are shown in Fig. 1A-D for IL6, IL12, TNF- $\alpha$ and IFN- $\gamma$ of each cell type. Incubation of BMDC with SZU101 alone stimulated cytokine release (Fig. 1A). IL12 and TNF- $\alpha$ production was concentration-dependent from 5 to $50 \mu \mathrm{M}$, comparing with the concentration of LPS at $100 \mu \mathrm{M}$, both IL12 and TNF- $\alpha$ production of SZU101-treated group was higher than LPS positive control. For NK cell, we detected the release of TNF- $\alpha$ and INF- $\gamma$ (Fig. 1B). We also used the mouse macrophage cell line RAW264.7 to evaluate the production of IL6 and TNF- $\alpha$, with similar results (Fig. 1C). SZU101 was able to stimulate lymphocytes to release cytokines, which were related with adopted immunity, at the very high level compared with other innate immunity cells at the same concentration (Fig. 1D).

Expression of TLR7 on immune cells and activation of $N F-\kappa B$ pathway. To confirm that SZU101 was indeed the TLR7 ligand, we detected the expression of TLR7 on immune cells by western blot analysis. BMDC were treated with SZU101 to identify endogenous TLR7 expression for innate immune and spleen lymphocytes for adoptive immune. The western blot results showed that the expression of TLR7 increased after the SZU101 treatment in a concentration-dependent manner (Fig. 2B). We also detected the expression of TLR7 on the 4T1 cells. There was no expression of TLR7 on the $4 \mathrm{~T} 1$ cells (Fig. 2A). For the activation of NF- $\kappa \mathrm{B}$ pathway, NF- $\kappa$ Bp65 was the key protein. NF- $\kappa \mathrm{B}$ activation was observed by detected p65 expression on both cytoplasm and the nucleus (Fig. 2C).

Intratumoral injection of SZU101 to 4 T1 tumor-bearing $B A L B / c$ mice can reduce tumor growth. $4 \mathrm{~T} 1$ tumor-bearing $\mathrm{BALB} / \mathrm{c}$ mice were treated every three days from day 7 to day 30 with SZU101 $(n=5)$ or PBS $(n=5)$. On day 30, the mice were sacrified, the weight of spleen, and both sides of the tumor was measured. As shown in Fig. 3, the mean spleen weight of tumor-bearing BALB/c mice was higher than the healthy mice. The 4T1 tumor cells increased the spleen size (Fig. 3B). 

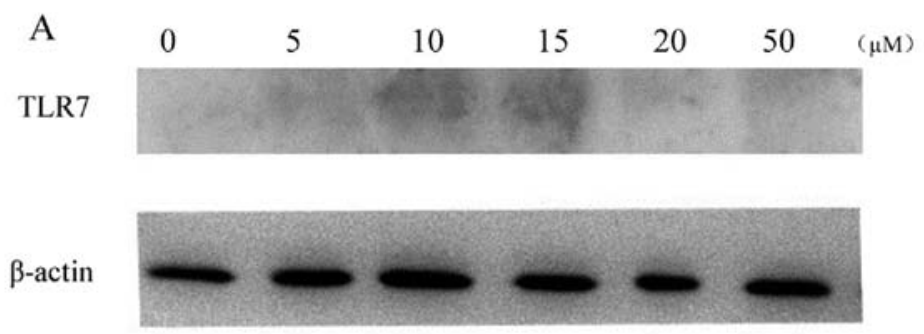

$4 \mathrm{~T} 1$ cell

$\mathrm{B}$

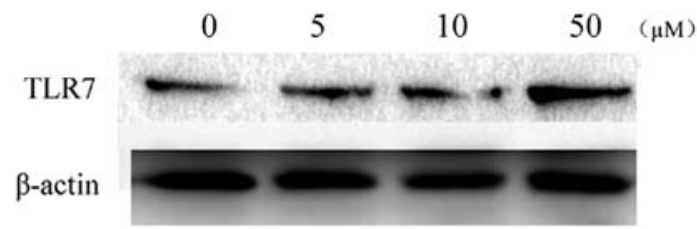

$\mathrm{C}$

TLR7

(cytoplasm) P65

(cytoplasm) І І B $\alpha$

$\beta$-actin

(nucleus) P65

GAPDH $\begin{array}{lll}0 & 10 \quad(\mu \mathrm{M})\end{array}$

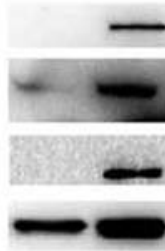
Figure 2. SZU101 induced the expression of TLR in 4T1 cells and BMDC, and activation of NF-kB via TLR7. 4T1 cells (A) and BMDC (B) were stimulated with SZU101 from 0 to $50 \mu \mathrm{M}$ for $12 \mathrm{~h}$. BMDC (C) were treated with 0 and $10 \mu \mathrm{M}$ SZU101 to detect the expression of P65 and IkB $\alpha$. Cell lysates were assessed by western blotting using the primary antibodies: IкB $\alpha, \mathrm{NF}-\kappa \mathrm{kp} 65$ and mTLR7.

A

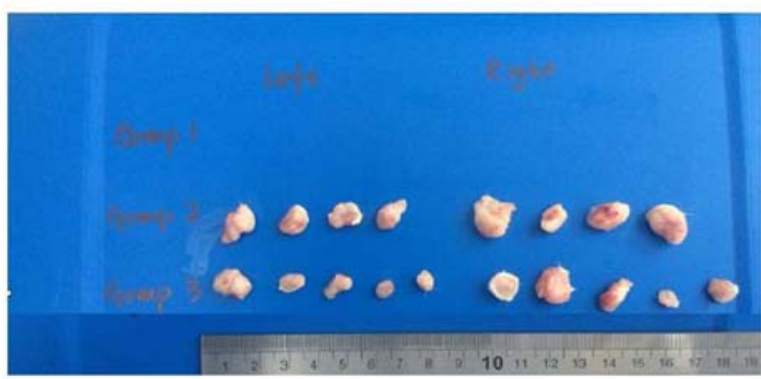

$\mathrm{C}$

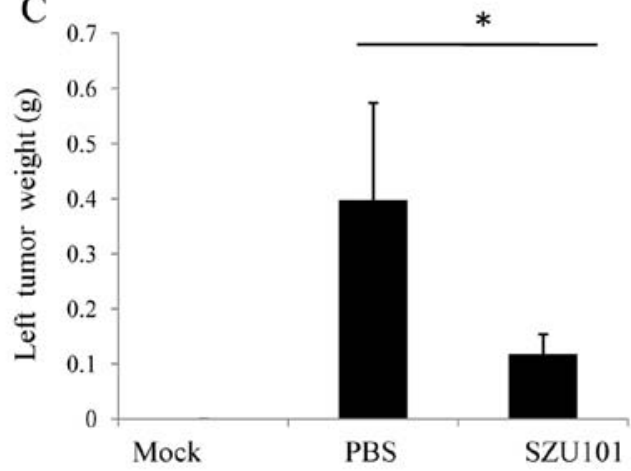

B

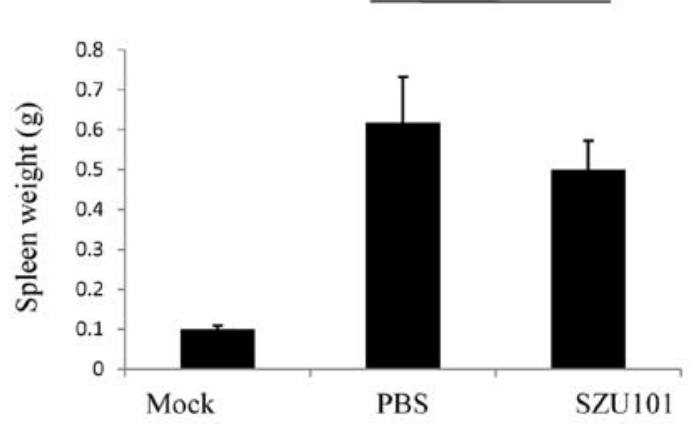

$\mathrm{D}$

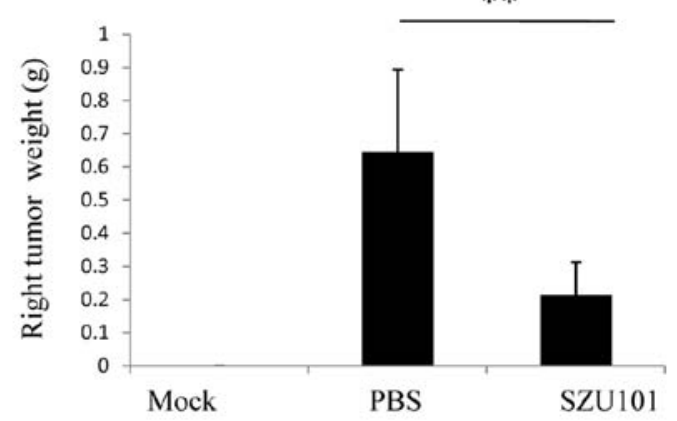

Figure 3. In vivo antitumor efficiency of SZU101. (A) A picture of the tumors from one of the groups. After 30 days, mice from each group were scarified and the weight of spleen (B) and tumors (C and D) was measured. Error bars indicate SD. Data are representative of three independent experiments. ${ }^{*}<0.05$, ${ }^{* *} \mathrm{P}<0.01$, respectively.

In our experiment, there was a positive correlation between the weight of the spleen and the tumor. When the tumor was large, the spleen was also large. Although SZU101 could reduce both sides of the tumors, it could not reduce the size of the spleen efficiently. We injected SZU101 into the right tumor (we called it local tumor), and the result showned that SZU101 inhibited the local tumor (Fig. 3D). We also found that the growth of the left tumor was inhibited (Fig. 3C). The results showed that intratumoral SZU101 injection in local tumor was inhibited on the other side of the tumor. 

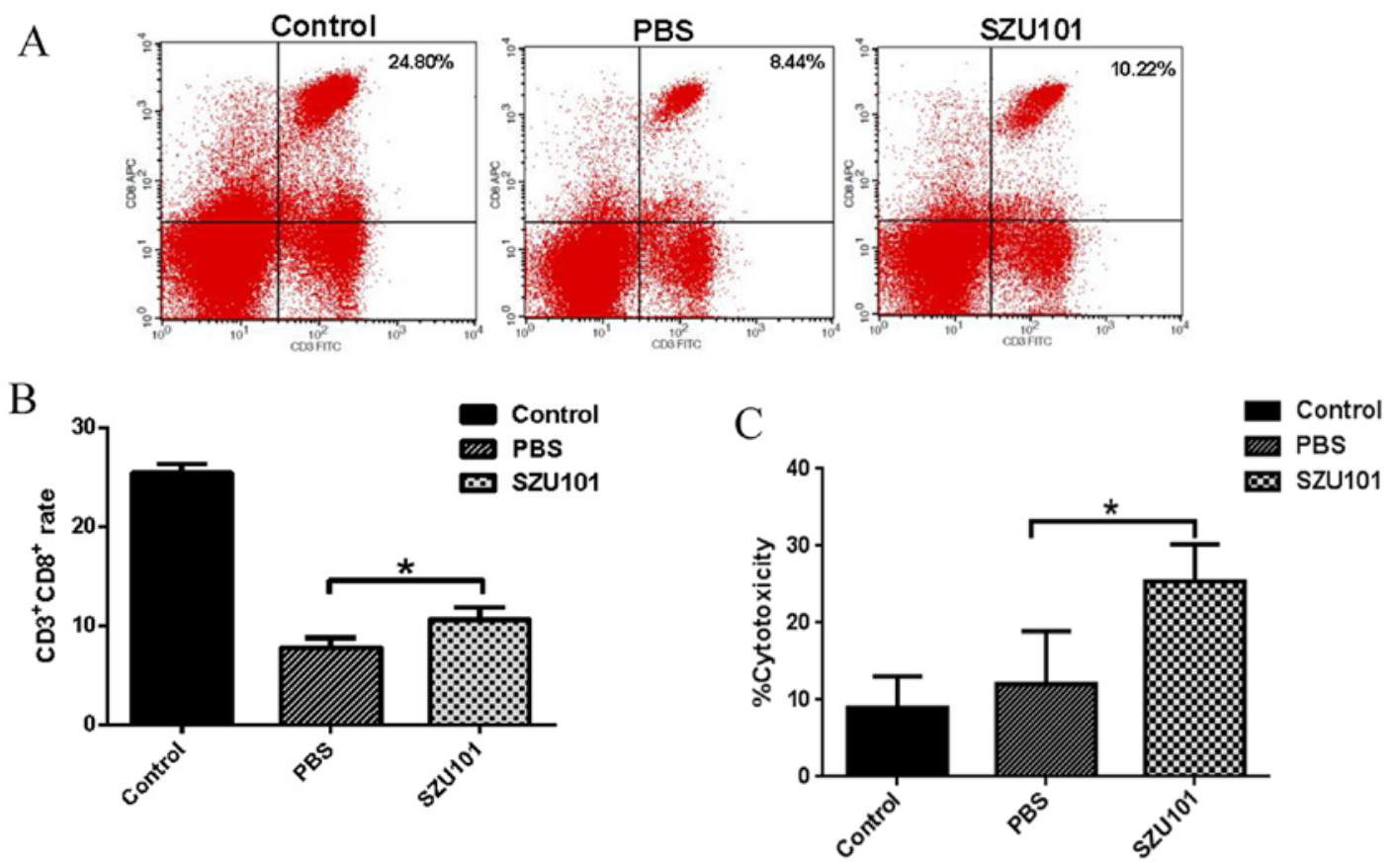

Figure 4. SZU101 induces systemic cellular immune response. (A and B) $\mathrm{CD}^{+} / \mathrm{CD} 8^{+} \mathrm{T}$ cells were gated and analyzed by FCM. Total splenocytes were labelled with APC-anti-mouse CD8 and FITC-anti-mouse CD3, and the percentages of $\mathrm{CD} 8^{+} / \mathrm{CD}^{+} \mathrm{T}$ cells in total splenocytes were measured. (C) Tumor-specific in vitro $\mathrm{CTL}$ response was measured as described in Materials and methods. Values represent means $\pm \mathrm{SD}\left(\mathrm{n}=5,{ }^{*} \mathrm{P}<0.05\right.$ and $\left.{ }^{* *} \mathrm{P}<0.01\right)$.
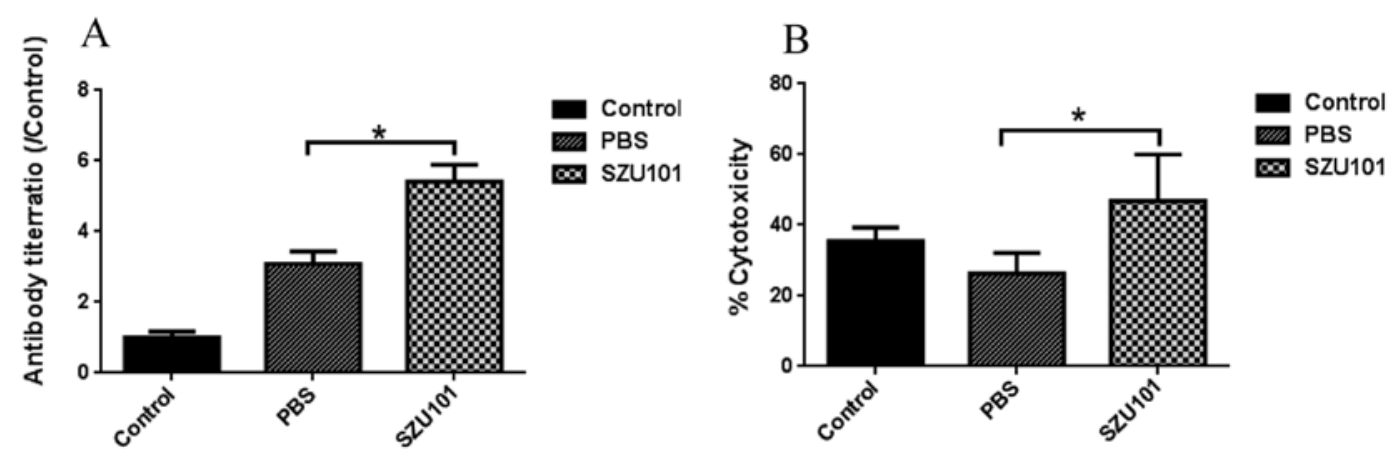

$\mathrm{C}$

$\mathrm{D}$
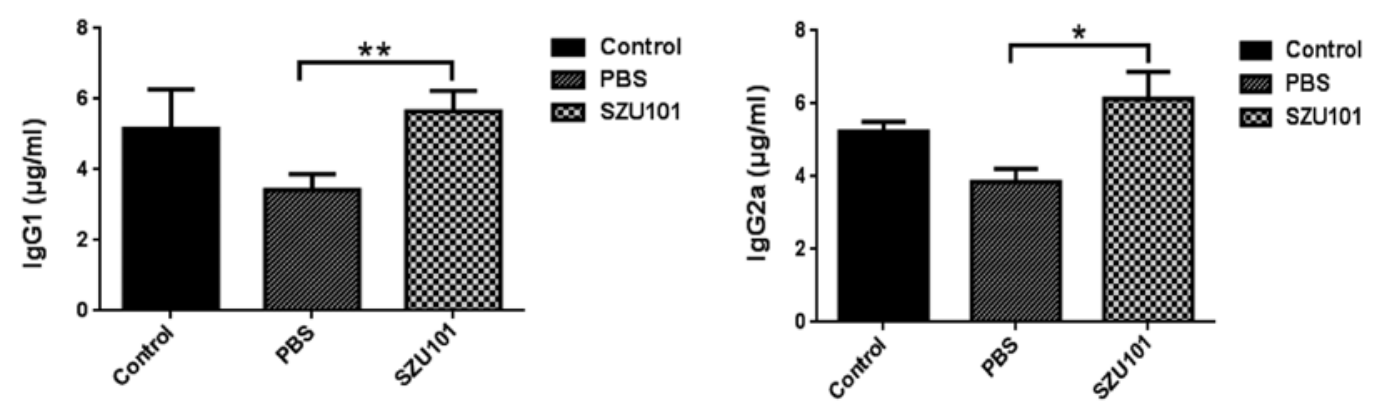

Figure 5. SZU101 induces humoral immune response. (A) Anti-4T1 antibody titers. (B) Induction of antibody-dependent cell-mediated cytotoxicity (ADCC). (C) IgG1 titers in serum. (D) IgG2a titers in serum. Values represent means $\pm \mathrm{SD}\left(\mathrm{n}=5,{ }^{*} \mathrm{P}<0.05\right.$ and $\left.{ }^{* * *} \mathrm{P}<0.01\right)$.

CTL assay. It has been demonstrated that the proportion of CD8 $\mathrm{T}$ cell not only in the TILs but also in the spleen was significant. To assess the ability of the SZU101 to activate CTLs, we determined the percentage of $\mathrm{CD}^{+} / \mathrm{CD}^{+} \mathrm{T}$ cells, and the cytotoxicity rates of splenic lymphocytes on 4T1 tumor cells. As shown in Fig. $4 \mathrm{~A}$, the percentages of $\mathrm{CD}^{+} / \mathrm{CD}^{+}$ $\mathrm{T}$ cells in group SZU101 are remarkably higher than that in the control (Fig. 4B). The cytotoxicity rates of 4T1 cells induced by splenic lymphocytes in group SZU101 is higher than that in the control (Fig. 4C).

The humoral immune assay. Serum antibody titers against 4T1 tumor cells were determined by ELISA assay coating microtiter plates with whole protein of 4T1 tumor cells. As 

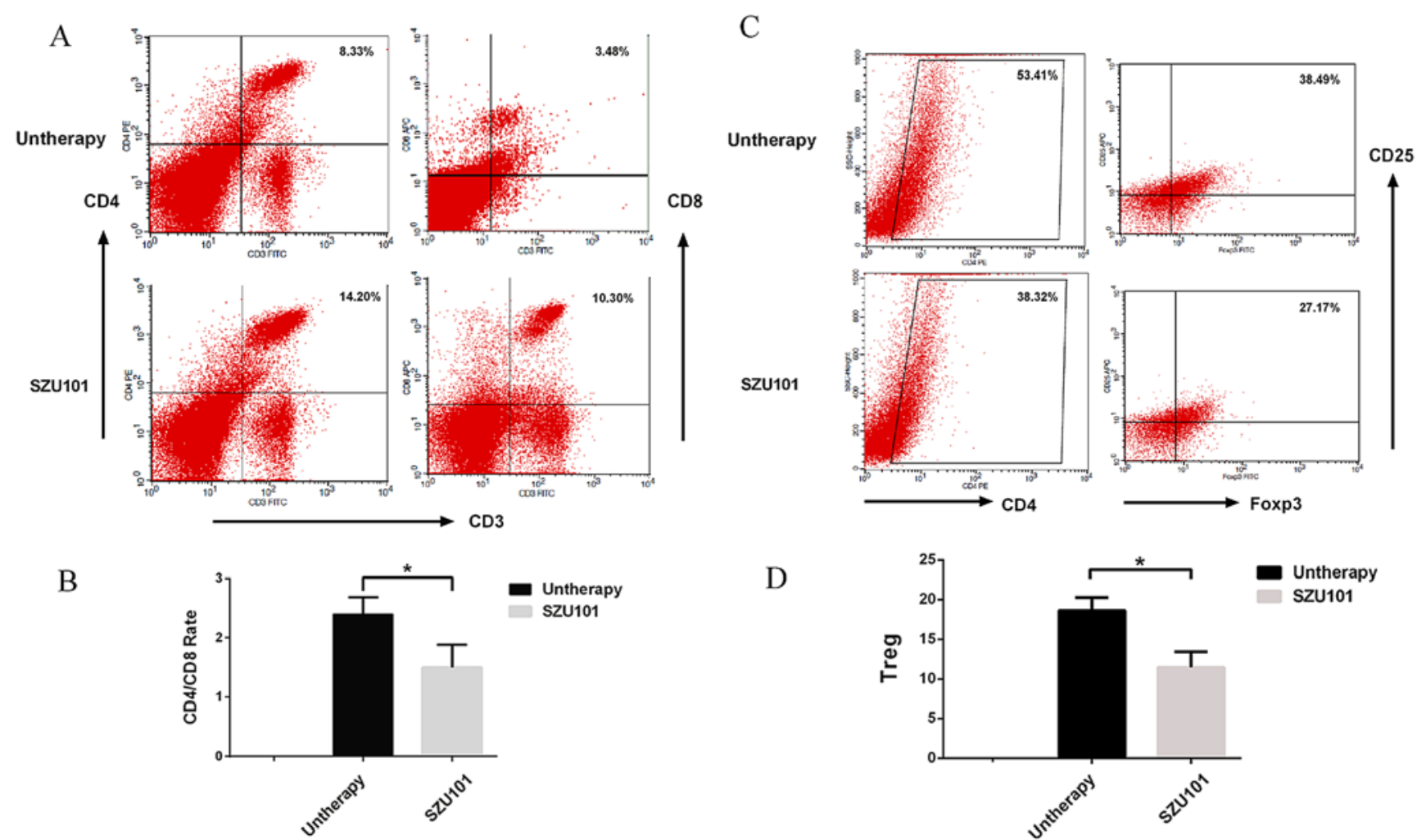

$\mathrm{D}$

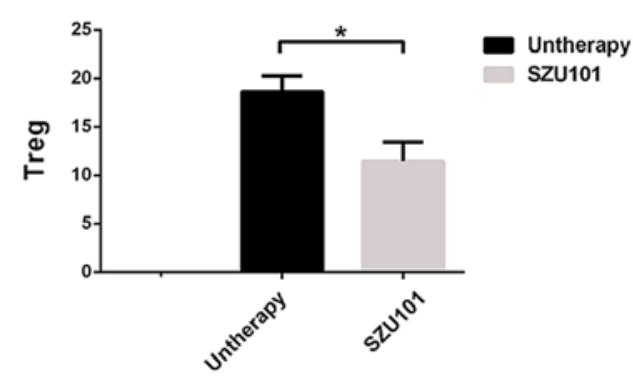

Figure 6. SZU101 effect on the frequency of intratumoral immune cell infiltration. (A) $\mathrm{CD} 4^{+} / \mathrm{CD}^{+} \mathrm{T}$ cells and $\mathrm{CD} 8^{+} / \mathrm{CD} 3^{+} \mathrm{T}$ cells were gated and analyzed by FCM. Total tumor infiltrated T cells were labeled with PE- anti-mouse CD4, APC-anti-mouse CD8 and FITC-anti-mouse CD3. (B The ratio of CD4 ${ }^{+} / \mathrm{CD}^{+}$ T cells was measured. (C) $\mathrm{CD} 25^{+} \mathrm{Foxp} 3^{+} \mathrm{CD} 4{ }^{+} \mathrm{T}$ cells were gated and analyzed by $\mathrm{FCM}$. Total tumor infiltrated $\mathrm{T}$ cells were labeled with PE-anti-mouse $\mathrm{CD} 4$, APC-anti-mouse CD25 and FITC-anti-mouse Foxp3. (D) The percentage of Tregs in both untreated and SZU101 treated group. Values represent means \pm SD $\left(\mathrm{n}=5,{ }^{*} \mathrm{P}<0.05\right.$ and $\left.{ }^{* *} \mathrm{P}<0.01\right)$.

shown in Fig. 5, 4T1 tumor cell antibody increased significantly in SZU101 group compared to control, but the control group also had high antibody titers (Fig. 5A). SZU101 was effective in eliciting $\operatorname{IgG}$ responses in serum, and these responses were generally dominated by $\operatorname{IgG} 2 \mathrm{a}$, which is thought to reflect Th1-driven response. IgG2a titers were significantly different between SZU101-treated group and control group (Fig. 5D). Antibody-dependent cell-mediated cytotoxicity (ADCC) was determined by addition of serum samples and NK cells (cytotoxic effector cells) to 4T1 tumor cells (target cells), and measurement of released LDH activity (Fig. 5B). Compared with PBS control, control group was not significantly different tumor from cell lysis. However, SZU101 treated group induced significant cancer cell lysis compared with the other two groups. ADCC is primarily mediated by $\mathrm{IgG1}$. IgG1 titers were increased in Fig. 5C.

SZU101 effect on the frequency of intratumoral immune cell infiltration. To examine the 4T1 tumor microenvironment in the treated mouse and to study if the treatment of tumor-bearing mice with SZU101 would lead to memory responses in the mice, we collected and processed distant tumors for analysis of infiltrating cells (Fig. 6). The percentage of T helper cells $\left(\mathrm{CD}^{+} / \mathrm{CD}^{+}\right)$in SZU101-treated mice significantly increased compared with untreated mice (Fig. 6A). We also found a strong increase of $\mathrm{CD}^{+} \mathrm{T}$ cells in the distant tumor (Fig. 6A). The $\mathrm{CD}^{+} / \mathrm{CD}^{+}$ratio was reduced in SZU101 treated group (Fig. 6B). To determine the effect of SZU101 treatment on Tregs at the distant tumor site, CD25 and Foxp3 expression on $\mathrm{CD} 4^{+}$cells was assessed by flow cytometry. The distribution of $\mathrm{CD} 25^{+}$, Foxp3 $3^{+}$, or $\mathrm{CD} 25^{+} \mathrm{Foxp}^{+}$(Treg) cells in the distant tumor are shown in Fig. 6C and D, respectively. In the distant tumor, the frequency of $\mathrm{CD} 25^{+} \mathrm{Foxp} 3^{+}$cells was significantly reduced in SZU101-treated mice compared with (Fig. 6D). The untreated mice had $38.49 \pm 2.1 \%$ Tregs (Fig. 6C), whereas mice treated with SZU101 had fewer Tregs at the distant tumor site $(27.17 \pm 3.6 \%, \mathrm{P}<0.05)$ (Fig. $6 \mathrm{C})$.

\section{Discussion}

For most solid tumors, surgery is still the main method, but small metastatic tumors cannot always be found and removed totally. Normally our immune systems are able to recognize tumor cells and remove them, but the tumor-bearing host loses the ability to recognize tumor cells as exogenous and fails to defend transformed cells. Immunotherapy attempts to stimulate the patient's own natural ability of the immune system to fight cancer, it is becoming increasingly widely used as more successful approaches are discovered (17). TLR agonists are of great interest in cancer immunotherapy (5). TLR agonists used as single agents especially when applied locally can effectively eradicate tumors due to their potent stimulation of innate and adaptive immunity as well as their effects on the tumor microenvironment $(6,18)$. In the present study, we set up a local administration strategy to trigger systemic antitumor immune response on a mouse 
breast cancer model. The antitumor effect of SZU101 was associated with TLR7 activation of both innate immune cells and adaptive immune cells, especially reversal of tolerance in tumor microenvironment.

Non-specific innate immune cells play an important role in cancer therapy, particularly in the elimination of tumor metastases and small tumors. Activited NK cells have not only the capacity to detect changes in transformed cells, but also the responsiblity for tumor rejection in a direct manner (19). Low natural killer (NK) activity has been reported as a high risk for developing malignancy (20). NK cells produce perforin to lyse tumor cells directly as shown in vivo and in vitro $(21,22)$. TLR agonists can increase NK cell activity to enhance antibody-dependent cell-mediated cytotoxicity (ADCC) $(23,24)$. NK cells produce type 1 cytokines such as IFN- $\gamma$ and TNF- $\alpha$ during tumor occurrence to further enhance their cytotoxicity and modulate the adaptive immune cells, such as dendritic cells and T cells (25). SZU101 stimulated NK cells to produce more TNF- $\alpha$ and INF- $\gamma$ than LPS control (Fig. 2B). In ADCC, the SZU101 group had higher ADCC activity than the other groups. There are two major kinds of macrophages: classical M1 and alternative M2 macrophages. The M1 macrophage can be activated by TLR agonists and INF- $\gamma$, and secrete high levels of TNF- $\alpha$, it is related to the inflammatory response, pathogen clearance, and antitumor immunity. In contrast, M2 macrophage influences an anti-inflammatory response, wound healing, and pro-tumorigenic properties $(26,27)$. Tumor-associated macrophages (TAMs) are considered mainly M2 macrophages with poor response to therapy (28). Activation of macrophages to the M1 phenotype leads to upregulation of several pro-inflammatory cytokines and chemokines (29). We utilized RAW264.7 as the model in vitro. The results showed that SZU101 stimulated RAW264.7 to produce high level of TNF- $\alpha$ and IL-6, which were markers of the M1 macrophage (Fig. 1C). In our study, SZU101 could not only elicit the non-specific antitumor responses but also strengthen the specific humoral and cellular immune responses. DCs play a crucial role in linking innate and adaptive immunity, and in the generation of a protective immune response against both infectious diseases and tumors. DCs are always immature in tumor microenvironment (30). Here, DCs were activated and matured by SZU101 in vitro, and we detected the secretion of IL12, TNF- $\alpha$ at a high secretive level (Fig. 1A). The major function of DCs is as professional antigen presenting cells (APCs) to induce naïve $\mathrm{T}$ cell into protective CD8 T cells and CD4 T helper cells. Antigen delivery to DCs and maturation of DCs is relevant to antitumor success. Our CTL assay data showed that SZU101 stimulated systemic antitumor CD8 T cell response. SZU101 was injected into local tumor site (right frank), but the distant tumor was inhibited at the same time (Fig. 2). It implied that SZU101 may induce the CD8 T cells into T memory cells and CTL to aim to distant tumor. Intratumoral administration of TLR7 agonist generated systemic antitumor immunity and suppressed both injected and distant, uninjected wild-type B16F10 melanomas in a recent study. It showed that CD8 T cells, B cells, type I IFN, IFN- $\gamma$ and plasmacytoid dendritic cells contributed to efficient tumor suppression (31). The microenvironment of solid tumor typically contains various cell subsets of the innate immune system (32). The immune cells have been shown to influence the immune system to promote either antitumor immunity, or tumor progression in the tumor microenvironment. Diederichsen et al showed a significantly higher 5-year survival in patients with a low $\mathrm{CD}^{+} / \mathrm{CD}^{+}$ratio in the tumor infiltrating lymphocytes (33). Bloomfield et al investigated the potential of locally delivered imiquimod in a murine model of malignant mesothelioma (AB1-HA) with primary and distal tumors (dual tumor). They found imiquimod injection locally could stimulate an effective systemic antitumor response required both CD8 T cells and NK cells, but not CD4 T cells (34).

$\mathrm{CD}^{+} \mathrm{T}$ cells within cancer nests were shown to be better predictors of outcome than the same cells found in other areas of the tumor in NSCLC (35). Similarly, tumor specific $\mathrm{CD}^{+} \mathrm{T}$ cell activity determines colorectal cancer patient prognosis (36). In accordance with these results, our results showed that infiltration of $\mathrm{CD} 8^{+} \mathrm{T}$ cells increased, and $\mathrm{CD}^{+} / \mathrm{CD}^{+} \mathrm{T}$ cells decreased in distant tumor by SZU101 injection (Fig. 6). As shown previously, SZU101 injection group delayed distant tumor growth. Clinical antitumor resistance has been correlated with increased intratumoral levels of immunosuppressive regulatory $\mathrm{T}$ cells (Tregs), and the phenotype of Tregs is $\mathrm{CD}^{+} / \mathrm{FOXP}^{+} / \mathrm{CD} 25^{+}(37)$. We detected Tregs in the distant tumor, and representative dot plots are displayed in Fig. 6C. The results suggested that SZU101 reduced the number of Tregs in the distant tumor microenvironment. Some studies showed that Treg cell-mediated suppression could be overcome by the stimulation of TLRs on DCs (4). In a recent study, loxoribin, one of the TLR7 ligands, inhibited tumor growth in xenograft models of colon cancer and lung cancer by reversing Treg-mediated suppression via dendritic cells (DCs) (38).

In conclusion, the immunostimulatory properties of TLR ligands have been exploited to increase the efficacy of cancer immunotherapy. Our results confirmed that SZU101 could induce both innate and adaptive immune cells to strong Th-1-bias immune responses and the release of proinflammatory cytokines, such as TNF- $\alpha$, IFN- $\gamma$, IL-6 and IL-12 in vitro. In a previous study, our group used SZU-101 to treat tumors in a murine model of T cell lymphoma. SZU-101 could activated TLR7 NF- $\kappa \mathrm{B}$ signaling in a TLR7-specific system at a low concentration of $1 \mu \mathrm{M}$ after $6 \mathrm{~h}$ of stimulation in vitro (15). The anticancer therapies given directly into tumors may be more effective than given systemically, because local therapies could overcome natural suppressive factors in the tumor microenvironment, and induce systemic antitumor immunity (39). For solid tumors, especially breast cancer, direct intratumoral injection is safe and effective (40). In the 4T1 mouse model of breast cancer, intratumoral administration of SZU101 generated systemic antitumor immunity and suppressed both injected and distant tumors. It implied that intratumoral immune activation could induce local and systemic antitumor immunity by SZU101. Our findings in the present study provide an effective breast cancer immunotherapy by targeting tumor microenvironment.

\section{Acknowledgements}

We thank Professor Dennis Carson, University of California at San Diego, USA, for excellent technical guidance. 
We also thank the National Natural Science Foundation of China (grant 81202396 and 81273374), the Science Foundation of Shenzhen (grant JCYJ20130326112757843 and JCYJ20130326110057374) and China Postdoctoral Science Foundation (grant 2013M542200) for providing financial support of the present study.

\section{References}

1. Barton GM and Medzhitov R: Toll-like receptors and their ligands. Curr Top Microbiol Immunol 270: 81-92, 2002.

2. Iwasaki A and Medzhitov R: Toll-like receptor control of the adaptive immune responses. Nat Immunol 5: 987-995, 2004.

3. Gibson SJ, Lindh JM, Riter TR, Gleason RM, Rogers LM, Fuller AE, Oesterich JL, Gorden KB, Qiu X, McKane SW, et al: Plasmacytoid dendritic cells produce cytokines and mature in response to the TLR7 agonists, imiquimod and resiquimod. Cell Immunol 218: 74-86, 2002.

4. van Duin D, Medzhitov R and Shaw AC: Triggering TLR signaling in vaccination. Trends Immunol 27: 49-55, 2006.

5. Paulos CM, Kaiser A, Wrzesinski C, Hinrichs CS, Cassard L, Boni A, Muranski P, Sanchez-Perez L, Palmer DC, Yu Z, et al: Toll-like receptors in tumor immunotherapy. Clin Cancer Res 13 : 5280-5289, 2007.

6. Adams S: Toll-like receptor agonists in cancer therapy. Immunotherapy 1: 949-964, 2009.

7. Lakshminarayanan V, Thompson P, Wolfert MA, Buskas T, Bradley JM, Pathangey LB, Madsen CS, Cohen PA, Gendler SJ and Boons GJ: Immune recognition of tumor-associated mucin MUC1 is achieved by a fully synthetic aberrantly glycosylated MUC1 tripartite vaccine. Proc Natl Acad Sci USA 109: 261-266, 2012.

8. Hurwitz AA and Watkins SK: Immune suppression in the tumor microenvironment: A role for dendritic cell-mediated tolerization of T cells. Cancer Immunol Immunother 61: 289-293, 2012

9. Cheng C, Qu QX, Shen Y, Lv YT, Zhu YB, Zhang XG and Huang JA: Overexpression of B7-H4 in tumor infiltrated dendritic cells. J Immunoassay Immunochem 32: 353-364, 2011.

10. Jochems C and Schlom J: Tumor-infiltrating immune cells and prognosis: The potential link between conventional cancer therapy and immunity. Exp Biol Med (Maywood) 236: 567-579, 2011.

11. Aranda F, Vacchelli E, Obrist F, Eggermont A, Galon J, Sautès-Fridman C, Cremer I, Henrik Ter Meulen J, Zitvogel L, Kroemer G, et al: Trial Watch: Toll-like receptor agonists in oncological indications. OncoImmunology 3: e29179, 2014.

12. Hemmi H, Kaisho T, Takeuchi O, Sato S, Sanjo H, Hoshino K, Horiuchi T, Tomizawa H, Takeda K and Akira S: Small anti-viral compounds activate immune cells via the TLR7 MyD88-dependent signaling pathway. Nat Immunol 3: 196-200, 2002.

13. Lee J, Chuang TH, Redecke V, She L, Pitha PM, Carson DA, Raz E and Cottam HB: Molecular basis for the immunostimulatory activity of guanine nucleoside analogs: Activation of Toll-like receptor 7. Proc Natl Acad Sci USA 100: 6646-6651, 2003.

14. Stary G, Bangert C, Tauber M, Strohal R, Kopp T and Stingl G: Tumoricidal activity of TLR7/8-activated inflammatory dendritic cells. J Exp Med 204: 1441-1451, 2007.

15. Zhu J, He S, Du J, Wang Z, Li W, Chen X, Jiang W, Zheng D and Jin G: Local administration of a novel Toll-like receptor 7 agonist in combination with doxorubicin induces durable tumouricidal effects in a murine model of $\mathrm{T}$ cell lymphoma. J Hematol Oncol 8: 21, 2015.

16. Zamarin D, Holmgaard RB, Subudhi SK, Park JS, Mansour M, Palese P, Merghoub T, Wolchok JD and Allison JP: Localized oncolytic virotherapy overcomes systemic tumor resistance to immune checkpoint blockade immunotherapy. Sci Transl Med 6: 226ra32, 2014

17. Stewart TJ and Smyth MJ: Improving cancer immunotherapy by targeting tumor-induced immune suppression. Cancer Metastasis Rev 30: 125-140, 2011.

18. Kanzler H, Barrat FJ, Hessel EM and Coffman RL: Therapeutic targeting of innate immunity with Toll-like receptor agonists and antagonists. Nat Med 13: 552-559, 2007.

19. Stojanovic A and Cerwenka A: Natural killer cells and solid tumors. J Innate Immun 3: 355-364, 2011

20. Whiteside TL: Immune suppression in cancer: Effects on immune cells, mechanisms and future therapeutic intervention. Semin Cancer Biol 16: 3-15, 2006.
21. Marcus A, Gowen BG, Thompson TW, Iannello A, Ardolino M, Deng W, Wang L, Shifrin N and Raulet DH: Recognition of tumors by the innate immune system and natural killer cells. Adv Immunol 122: 91-128, 2014

22. Cho D1, Shook DR, Shimasaki N, Chang YH, Fujisaki H and Campana D: Cytotoxicity of activated natural killer cells against pediatric solid tumors. Clin Cancer Res 16: 3901-3909, 2010.

23. Moreno M, Mol BM, von Mensdorff-Pouilly S, Verheijen RH, von Blomberg BM, van den Eertwegh AJ, Scheper RJ and Bontkes HJ: Toll-like receptor agonists and invariant natural killer T-cells enhance antibody-dependent cell-mediated cytotoxicity (ADCC). Cancer Lett 272: 70-76, 2008.

24. Lauzon NM, Mian F, MacKenzie R and Ashkar AA: The direct effects of Toll-like receptor ligands on human NK cell cytokine production and cytotoxicity. Cell Immunol 241: 102-112, 2006.

25. Vivier E, Raulet DH, Moretta A, Caligiuri MA, Zitvogel L, Lanier LL, Yokoyama WM and Ugolini S: Innate or adaptive immunity? The example of natural killer cells. Science 331: 44-49, 2011

26. Chanmee T, Ontong P, Konno K and Itano N: Tumor-associated macrophages as major players in the tumor microenvironment. Cancers (Basel) 6: 1670-1690, 2014.

27. Mosser DM and Edwards JP: Exploring the full spectrum of macrophage activation. Nat Rev Immunol 8: 958-969, 2008.

28. Ostuni R, Kratochvill F, Murray PJ and Natoli G: Macrophages and cancer: From mechanisms to therapeutic implications. Trends Immunol 36: 229-239, 2015.

29. Lopez-Castejón G, Baroja-Mazo A and Pelegrín P: Novel macrophage polarization model: From gene expression to identification of new anti-inflammatory molecules. Cell Mol Life Sci 68: 3095-3107, 2011

30. Ullrich E, Ménard C, Flament C, Terme M, Mignot G, Bonmort M, Plumas J, Chaperot L, Chaput N and Zitvogel L: Dendritic cells and innate defense against tumor cells. Cytokine Growth Factor Rev 19: 79-92, 2008.

31. Singh M, Khong H, Dai Z, Huang XF, Wargo JA, Cooper ZA, Vasilakos JP, Hwu P and Overwijk WW: Effective innate and adaptive antimelanoma immunity through localized TLR7/8 activation. J Immunol 193: 4722-4731, 2014.

32. Mao Y, Keller ET, Garfield DH, Shen K and Wang J: Stromal cells in tumor microenvironment and breast cancer. Cancer Metastasis Rev 32: 303-315, 2013.

33. Diederichsen AC, Hjelmborg J, Christensen PB, Zeuthen J and Fenger C: Prognostic value of the $\mathrm{CD}^{+} / \mathrm{CD}^{+}$ratio of tumour infiltrating lymphocytes in colorectal cancer and HLA-DR expression on tumour cells. Cancer Immunol Immunother 52: 423-428, 2003

34. Broomfield SA, van der Most RG, Prosser AC, Mahendran S, Tovey MG, Smyth MJ, Robinson BW and Currie AJ: Locally administered TLR7 agonists drive systemic antitumor immune responses that are enhanced by anti-CD40 immunotherapy. J Immunol 182: 5217-5224, 2009.

35. Hiraoka K, Miyamoto M, Cho Y, Suzuoki M, Oshikiri T, Nakakubo $Y$, Itoh $T$, Ohbuchi $T$, Kondo $S$ and Katoh $H$ : Concurrent infiltration by $\mathrm{CD} 8^{+} \mathrm{T}$ cells and $\mathrm{CD} 4^{+} \mathrm{T}$ cells is a favourable prognostic factor in non-small-cell lung carcinoma. Br J Cancer 94: 275-280, 2006.

36. Reissfelder C, Stamova S, Gossmann C, Braun M, Bonertz A, Walliczek U, Grimm M, Rahbari NN, Koch M, Saadati M, et al: Tumor-specific cytotoxic T lymphocyte activity determines colorectal cancer patient prognosis. J Clin Invest 125: 739-751, 2015.

37. Yamaguchi $\mathrm{T}$ and Sakaguchi S: Regulatory $\mathrm{T}$ cells in immune surveillance and treatment of cancer. Semin Cancer Biol 16: 115-123, 2006.

38. Wang C, Zhou Q, Wang X, Wu X, Chen X, Li J, Zhu Z, Liu B and Su L: The TLR7 agonist induces tumor regression both by promoting $\mathrm{CD}^{+} \mathrm{T}$ cells proliferation and by reversing $\mathrm{T}$ regulatory cell-mediated suppression via dendritic cells. Oncotarget 6: 1779-1789, 2015

39. Nelson D, Fisher S and Robinson B: The 'Trojan Horse' approach to tumor immunotherapy: Targeting the tumor microenvironment. J Immunol Res 2014: 789069, 2014.

40. Van der Jeught K, Bialkowski L, Daszkiewicz L, Broos K, Goyvaerts C, Renmans D, Van Lint S, Heirman C, Thielemans K and Breckpot K: Targeting the tumor microenvironment to enhance antitumor immune responses. Oncotarget 6: 1359-1381, 2015. 